\title{
A study of metabolic parameters in non diabetic patients with non alcoholic fatty liver disease - importance of dyslipidemia
}

\author{
Gautam RAY ${ }^{1}$ and Trilochan AGARWALA ${ }^{2}$
}

Received 4/1/2019 Accepted 25/6/2019

\begin{abstract}
Background - Metabolic risk factors of non alcoholic fatty liver disease (NAFLD) in non diabetic teetotallers who constitute a definite group are not well defined. Objective - To identify the metabolic risk factors of NAFLD if any in non diabetic subjects who do not consume alcohol. Methods - In a cross sectional study the effect of metabolic parameters (BMI, individual lipid levels, hemoglobinA1c (HbA1c), HOMA IR and the metabolic syndrome components) of 150 consecutive non diabetic teetotallers (90 with normal glucose tolerance and 60 prediabetics) on their NFS (quantifiable severity parameter of NAFLD) was studied by linear regression analysis. Similar study was done in the normal glucose tolerance and prediabetes groups separately. These parameters were then compared with those of 75 matched diabetic teetotallers with NAFLD. To analyse further the difference between normal glucose tolerance, prediabetic and overt diabetic groups, binary logistic regression of the factors was carried out taking prediabetes and diabetes as outcome variable. Results - All the metabolic parameters were significantly higher in diabetics compared to non diabetics and in prediabetics compared to those with normal glucose tolerance except high-density lipoprotein cholesterol. Triglyceride, high-density lipoprotein cholesterol and BMI significantly predicted NFS in the overall (adjusted $\mathrm{R}^{2} 68.7 \%, P=0.000$ ) and normal glucose tolerance groups (adjusted $\mathrm{R}^{2} 73.2 \%$, $P=0.000$ ) whereas BMI, triglyceride, low-density lipoprotein cholesterol and HbA1c did in prediabetics (adjusted $\mathrm{R}^{2} 89 \%, P=0.000$ ). The metabolic syndrome was significantly associated with NFS in the overall and prediabetic groups. High triglyceride (odds ratio1.08), low-density lipoprotein cholesterol (odds ratio1.03) and HbA1c (odds ratio 11.54) were positively associated with prediabetes compared to normal glucose tolerance group.

Conclusion - In nondiabetic teetotallers dyslipidemias are the prime contributors to the development of NAFLD.

HEADINGS - Non alcoholic fatty liver disease. Dyslipidemias. Glycated hemoglobin A. Insulin resistance.
\end{abstract}

\section{INTRODUCTION}

The prevalence of non alcoholic fatty liver disease (NAFLD) in Indian population ranges from $5 \%$ to $28 \%$, which is comparable to the West ${ }^{(1)}$. It is common in patients suffering from type 2 diabetes mellitus (DM), obesity, hyperlipidemias and its prevalence increases with the number of these comorbidities. However, NAFLD occurs in a good number of patients without DM also. A number of Indian studies $^{(2-11)}$ show that though there is high prevalence of insulin resistance (IR) $(46 \%-83 \%)$ in such population, the prevalence of DM is only $4 \%-35 \%$ indicating that some other factor(s) is involved in the pathogenesis of NAFLD in them. There is high prevalence of obesity $(56 \%-80 \%)$ in them but the separate contribution of dyslipidemia is not clear (though its prevalence is high $50 \%-62 \%$ ) because it occurs simultaneously with other risk factors. Many authors believe that NAFLD in such population is a forerunner of future DM and the metabolic syndrome. Most studies also accept alcohol intake in doses of less than $30 \mathrm{~g} /$ day in men and $20 \mathrm{~g} /$ day in women as noncontributory to the development of fatty liver (as per definition) and include such patients but it can be a source of bias especially since self reported information on alcohol intake like the exact amount and duration is frequently subjected to under reporting and alcohol can cause raised triglyceride (TG) levels. Even the latest definition of NAFLD accepts that fixing any quantitative threshold on the dose of alcohol for the diagnosis of NAFLD will be at least partly arbitrary ${ }^{(12)}$. In order to clarify these issues we conducted a study of the metabolic parameters of a group of non diabetic teetotaller subjects having NAFLD to ascertain their association if any in this population and further compared these parameters to those of a diabetic teetotaller group with NAFLD to ascertain any difference.

NAFLD fibrosis score (NFS) is a quantifiable non invasive method of assessing the severity of NAFLD (including risk of fibrosis) calculated from six routinely used parameters which are found to be independently associated with advanced fibrosis. By applying a low cut-off $(<-1.455)$, advanced fibrosis can be excluded with high accuracy (negative predictive value $93 \%$ ) while a high cut-off threshold $(>0.676)$ offers accurate detection of advanced fibrosis (positive predictive value $90 \%)^{(13)}$. This score is thus a direct measure of severity and has been independently validated in other studies ${ }^{(14,15)}$ (i.e. $<-1.455=$ absence of significant NAFLD, -1.455 to $0.676=$ mild to moderate NAFLD and $>0.676=$ severe NAFLD) and recommended for severity assessment ${ }^{(12-16)}$. Due to non availability of fibroscan at the time of inception of the study and as none of our subjects consented for liver biopsy, we chose to study the weightage of these metabolic factors in predicting this quantifiable parameter of NAFLD as a measure of their degree of association.

Declared conflict of interest of all authors: none

Disclosure of funding: no funding received

${ }^{1}$ B.R.Singh Hospital Kolkata, Department of Medicine, Gastroenterology Unit, West Bengal, India. ${ }^{2}$ B.R.Singh Hospital Kolkata, Department of Medicine, West Bengal, India.

Corresponding author: Gautam Ray. E-mail: gautam1910@yahoo.com 


\section{METHODS}

The study included 150 consecutive non diabetic, teetotaller subjects recruited from outdoor and indoor services of our referral hospital from January 2012 to December 2016. NAFLD was diagnosed when they underwent ultrasonogram of abdomen in the fasting state for indications of liver function test abnormalities, gastrointestinal symptoms or as part of routine work up for other causes e.g. fever, preplacement examination etc. Detailed history (especially hypopituitarism, hypo/hyperthyroidism, Cushing syndrome, diabetes mellitus, chronic hepatitis $\mathrm{C}$, use of steatogenic drug like estrogens, amiodarone, tamoxifen, methotrexate or antituberculous drugs which can cause liver enzyme elevation) was elicited and clinical examination to look for any evidence of endocrine or chronic liver disease was done during initial screening. We excluded patients with history of above endocrine disorders, drugs use and clinical suspicion or ultrasonogram evidence of chronic liver disease or portal hypertension. Secondary causes of liver disease were excluded by negative tests for $\mathrm{HBsAg}$, Anti HCV, autoimmune liver disease antibodies, anti tissue transglutaminase antibodies with normal serum ceruloplasmin and iron studies. Alcohol intake was excluded by eliciting the history from patients, their relatives and friends, CAGE questionnaire and further confirmed by normal alkaline phosphatase and gamma glutamyltranspeptidase value. Patients with any amount of alcohol intake were excluded from the study.

\section{The metabolic parameters were measured as follows:}

Body mass index (BMI) was calculated using Quetelet index formula upon recording weight to the nearest half-kilogram with light clothes and bare feet, and height standing bare feet. ${ }^{(17)}$ Patients were graded as follows: underweight $\left(<18.5 \mathrm{~kg} / \mathrm{m}^{2}\right)$, normal BMI $\left(18.5-22.9 \mathrm{~kg} / \mathrm{m}^{2}\right)$, overweight $\left(23.0-24.9 \mathrm{~kg} / \mathrm{m}^{2}\right)$ and obese $(\geq 25$ $\left.\mathrm{kg} / \mathrm{m}^{2}\right)$ (according to the revised consensus guidelines for obesity for India) ${ }^{(18)}$. Blood pressure was measured in sitting position after 30 minutes of rest using a sphygmomanometer. Waist circumference was measured with the help of a non-stretchable measurement tape at the level just above the iliac crest at the end of expiration ${ }^{(19)}$.

The metabolic syndrome was defined by the criteria framed by the International Diabetes Federation Global Consensus Definition $^{(20)}$ i.e. Central obesity ( $>90 \mathrm{~cm}$ for men, $>80 \mathrm{~cm}$ for women) plus any two of the following four parameters: (1) Raised TG: $\geq 150$ $\mathrm{mg} / \mathrm{dL}$ or history of specific treatment for this lipid abnormality (2) Reduced high-density lipoprotein cholesterol (HDL): $<40 \mathrm{mg} / \mathrm{dL}$ in males and $<50 \mathrm{mg} /$ in females or history of specific treatment for this lipid abnormality. (3) Raised blood pressure: systolic $\geq 130$ $\mathrm{mm} \mathrm{Hg}$ or diastolic $\geq 85 \mathrm{~mm} \mathrm{Hg}$ or on treatment for previously diagnosed hypertension and (4) Raised fasting blood glucose (FBG) $\geq 100 \mathrm{mg} / \mathrm{dL}$ or previously diagnosed DM.

After an overnight fast, blood was collected for the following investigations: (1) FBG and 2 hour post load (75 g) plasma glucose (oral glucose tolerance test - OGTT) (by glucose oxidase-peroxidase method), (2) serum total cholesterol (TC), TG, HDL, bilirubin, aspartate aminotransferase (AST), alanine aminotransferase (ALT), alkaline phosphatase, gamma glutamyltranspeptidase, total protein, albumin and globulin (by Autoanalyzer using standard kits). Low-density lipoprotein cholesterol (LDL) was calculated using the Friedewald equation. HDL values less than $40 \mathrm{mg} / \mathrm{dL}$ in males and $50 \mathrm{mg} / \mathrm{dL}$ in females was considered abnormal. (3) Hemoglobin Alc (HbAlc) was measured by high-performance liquid chromatography. (4) Serum fasting insulin level was estimated by chemiluminescence immunoassay. (5) Baseline complete hemogram, thyroid function test, growth hormone and cortisol levels. All tests were done in the pathology department of the hospital.

Non diabetics were defined as those having FBG $<126 \mathrm{mg} /$ $\mathrm{dL}$ and $2 \mathrm{hr}$ OGTT $<200 \mathrm{mg} / \mathrm{dL}$. The overall group of $150 \mathrm{non}$ diabetics (Group 1) were subdivided into 2 categories: (a) normal glucose tolerance (NGT), $n=90$, group 1a and (b) prediabetics $(\mathrm{PD}), \mathrm{n}=60$, group $1 \mathrm{~b}$ (TABLE 1 ) which constituted those with impaired fasting glucose (IFG) and IGT.

TABLE 1. Categories of patients in study.

\begin{tabular}{lccc}
\hline Categories & FBG & $\begin{array}{c}2 \mathrm{hr} \\
\text { OGTT }\end{array}$ & $\begin{array}{c}\text { Number } \\
\text { of cases }\end{array}$ \\
\hline $\begin{array}{l}\text { (1) Non diabetics with normal } \\
\text { glucose tolerance (NGT, 1a) }\end{array}$ & $\begin{array}{c}<100 \\
\mathrm{mg} / \mathrm{dL}\end{array}$ & $\begin{array}{c}<140 \\
\mathrm{mg} / \mathrm{dL}\end{array}$ & 90 \\
(2) Prediabetics (PD, 1b) & & & 60 \\
(a) IFG and IGT & $\begin{array}{c}100-125 \\
\mathrm{mg} / \mathrm{dL}\end{array}$ & $\begin{array}{c}140-200 \\
\mathrm{mg} / \mathrm{dL}\end{array}$ & 20 \\
& $\begin{array}{c}100-125 \\
\mathrm{mg} / \mathrm{dL}\end{array}$ & $\begin{array}{c}<140 \\
\mathrm{mg} / \mathrm{dL}\end{array}$ & 25 \\
(b) Isolated IFG & $\begin{array}{c}<00 \\
\mathrm{mg} / \mathrm{dL}\end{array}$ & $\begin{array}{c}140-200 \\
\mathrm{mg} / \mathrm{dL}\end{array}$ & 15 \\
\hline
\end{tabular}

FBG: fasting blood glucose; OGTT: oral glucose tolerance test, OGTT: oral glucose tolerance test; IFG: impaired fasting glucose; IGT: impaired glucose tolerance.

Insulin resistance was calculated using the Homeostasis Model of Assessment for Insulin Resistance (HOMA-IR) formula: fasting insulin $(\mathrm{mIU} / \mathrm{mL}) \times$ fasting glucose $(\mathrm{mmol} / /$ liter $) / 22.5$. Those with values $>2$ were considered to have $\operatorname{IR}^{(21)}$.

NFS was calculated by the formula $-(-1.675+0.037 \times$ age (years) $+0.094 \times$ BMI $\left(\mathrm{kg} / \mathrm{m}^{2}\right)+1.13 \times \mathrm{IFG}$ or diabetes (yes $=1$, no $=0)+0.99 \times$ AST/ALT ratio $-0.013 \times$ platelet $\left(\times 10^{9} / \mathrm{L}\right)-0.66 \times$ albumin $(\mathrm{g} / \mathrm{dL})^{(13)}$.

Subsequently all the above parameters of the non diabetic group were compared to those of a group of 75 age and sex matched diabetic teetotaller subjects with NAFLD (Group 2) recruited from outdoor and indoor hospital services.

\section{Statistical analysis}

The minimum sample size needed for the cross sectional observational study of metabolic abnormalities in non diabetic NAFLD population (based on an estimated 50\% prevalence with $10 \%$ precision) was ascertained to be 100 .

Continuous variables were expressed as mean \pm standard deviation (SD) and categorical variables as proportions (\%). Univariate analysis of differences was carried out with Fischer's exact test for categorical variables and Student's $t$ test for continuous data. A two tailed $P$ value of $<0.05$ was considered significant. Multiple linear regression was carried out taking NAFLD fibrosis score as the outcome variable and the metabolic parameters as independent variables for group 1 and its subgroups $1 \mathrm{a}$ and $1 \mathrm{~b}$ separately. To analyse further the factors that may predict progress from NGT to $\mathrm{PD}$ and from non diabetic state to DM, binary logistic regression of the factors was carried out between Group 1a and $1 \mathrm{~b}$ taking prediabetes as outcome variable and between Group 1 and Group 2 considering DM as outcome variable. Odds ratio (OR) and confidence intervals (CI) were calculated. All statistical analysis was done with SPSS version 13 (Chicago Inc). 
All procedures performed were in accordance with the ethical standards of the institutional and/or national research committee and with the 1964 Helsinki declaration and its later amendments or comparable ethical standards. Informed consent was obtained from all patients to be included in the study and the study was approved by the hospital Ethics Committee.

\section{RESULTS}

Ultrasonogram of the abdomen (which diagnosed NAFLD) was done for the following reasons: (a) only right upper quadrant pain with normal liver enzymes in $25(16.7 \%)$, (b) asymptomatic elevation of ALT with/without elevation of AST in $50(33.3 \%)$ and (c) right upper quadrant pain and elevation of AST/ALT in 45 $(30 \%)$ and (d) incidental finding in $30(20 \%)$ subjects. Incidentally, associated symptoms of functional bowel disease was present in $93(62 \%)$ cases [irritable bowel syndrome as defined by ROME III criteria in $33(22 \%)$, dyspepsia in $18(12 \%)$ and a combination in $42(28 \%)]$.

Demographic and metabolic parameters of the three groups are shown in TABLES 2, 3. Majority i.e. $87(58 \%)$ were in 4 th and 5 th decade of life $[42(28 \%)$ were $<40$ years age, $30 / 90(33.3 \%)$ of NGT group and $12 / 60(20 \%)$ of PD group]. PD patients tended to be slightly older than NGT group though the difference was not statistically significant and there was female preponderance in all groups.

TABLE 2. Comparison of demographic and metabolic parameters of NGT and PD group.

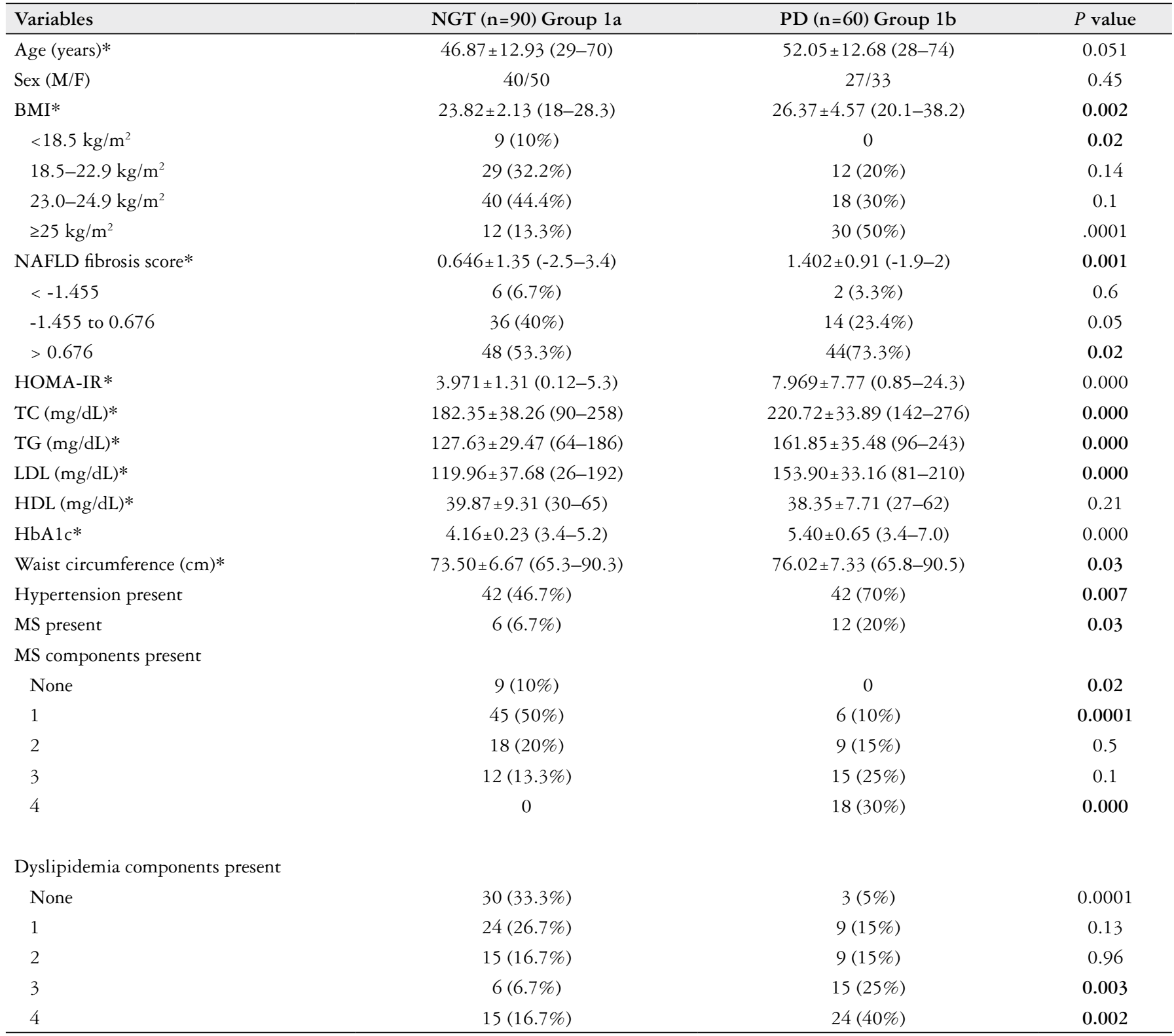

*Variables represented as mean \pm standard deviation (range). NGT: normal glucose tolerance; PD: prediabetics; NAFLD: non alcoholic fatty liver disease; TC: total cholesterol; TG: triglyceride; LDL: low-density lipoprotein cholesterol; HDL: high-density lipoprotein cholesterol; HbA1c: hemoglobinA1c; MS: metabolic syndrome. 
TABLE 3. Comparison of demographic and metabolic parameters of non diabetic and diabetic groups.

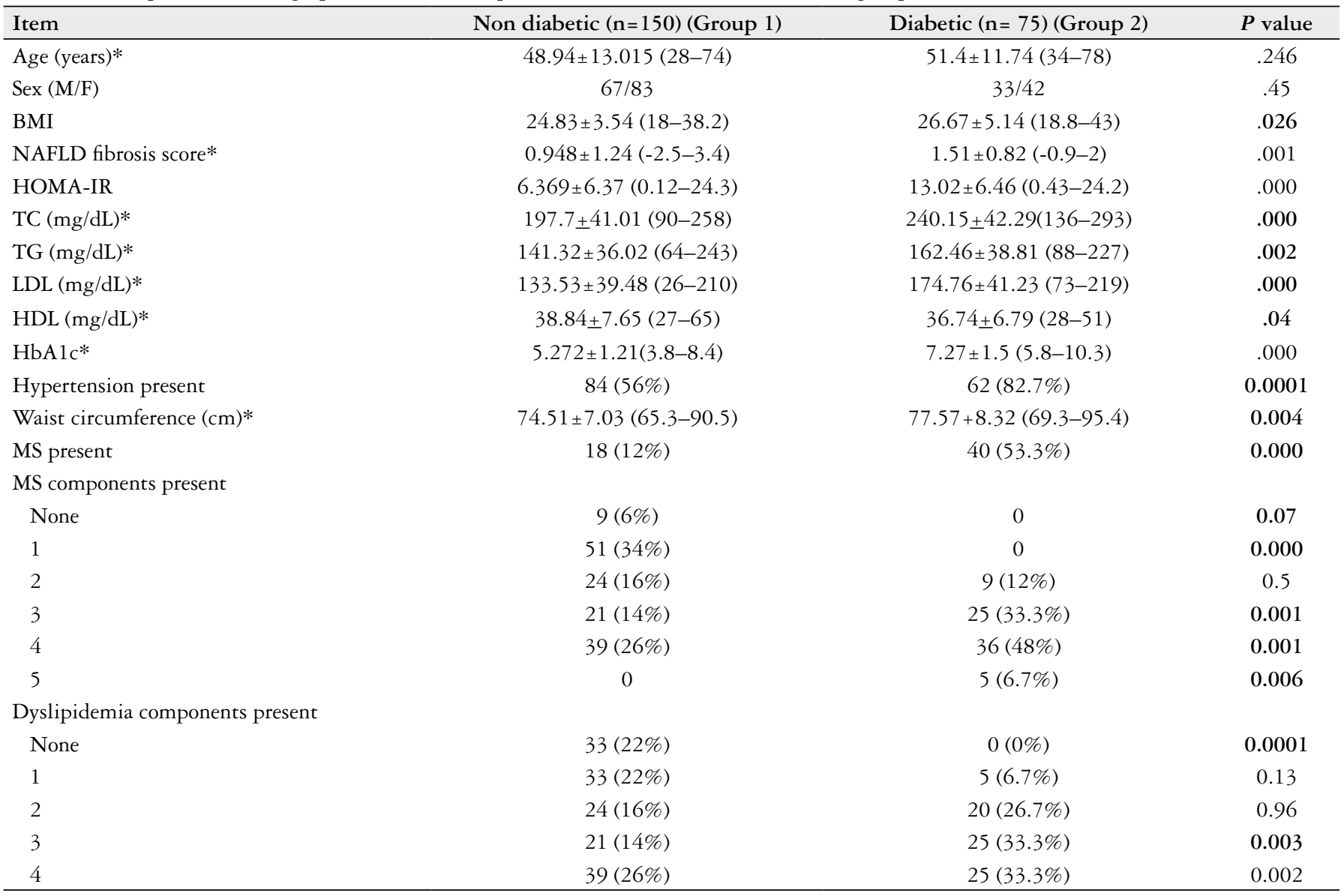

*Variables represented as mean \pm standard deviation (range), MS: metabolic syndrome; BMI: body mass index; NAFLD: non alcoholic fatty liver disease; HOMA-IR: homeostasis model of assessment for insulin resistance; TC: total cholesterol; TG: triglyceride; LDL: low-density lipoprotein cholesterol; HDL: high-density lipoprotein cholesterol; HbA1c: hemoglobinA1c; MS: metabolic syndrome.

Overall dyslipidemias were present in 78\% subjects of group 1 with raised TC in $42 \%$, TG in $52 \%$ and $\mathrm{LDL}$ in $44 \%(>129 \mathrm{mg} / \mathrm{dL})$ [or $75 \%$ (>100 mg/dL)]. HDL was low in $45(54 \%)$ females and 37 $(55 \%)$ males and $26 / 33(78.8 \%)$ of single dyslipidemias was a HDL abnormality. HbAlc was high in $36 \%$ [12 (6.7\%) in NGT group and $42(70 \%)$ in PD group, $P=0.000)]$.

All metabolic parameters (except HDL) as also BMI were significantly higher in PD compared to NGT group and in diabetics compared to overall non diabetic group 1.

Overall HOMA IR >2 (i.e.IR) was present in 76\% cases and significantly more number of patients in NGT group $(30 / 90=$ $33.3 \%)$ had normal HOMA IR compared to PD group $(6 / 60=10 \%)$ $(P=0.03)$.

The prediction of NFS by various metabolic factors in different groups is represented in TABLE 4. Increasing BMI and TG were common predictors in both NGT and PD groups, decreasing HDL was significant in the NGT group only while increasing LDL, $\mathrm{HbAlc}$ and presence of the metabolic syndrome (including high TG and hypertension) in the PD group only.

In the multivariate model, TG [OR 1.08 (CI 1.02-1.13)], HbA1c [OR 11.54 (CI 4.65-28.66)] and LDL [OR 1.03 (CI 1.002-1.06)] were positively associated with PD compared to NGT group $\left(\mathrm{R}^{2}\right.$ $66.7 \%$ ). HOMA IR was also a factor in the model but failed to reach
TABLE 4. Significance of factors in predicting NFS in various groups on linear regression analysis.

\begin{tabular}{lccc}
\hline Factors & $\begin{array}{c}\text { Overall } \\
\text { (Group 1) }\end{array}$ & $\begin{array}{c}\text { NGT } \\
\text { (Group 1a) }\end{array}$ & $\begin{array}{c}\text { PD } \\
\text { (Group 1b) }\end{array}$ \\
\hline Age & 0.23 & 0.6 & 0.9 \\
Sex & 0.5 & 0.4 & 0.3 \\
BMI & 0.000 & 0.000 & 0.001 \\
HOMA-IR & 0.12 & 0.5 & 0.2 \\
TG & 0.000 & 0.000 & 0.000 \\
LDL & $\mathbf{0 . 0 0 0}$ & 0.3 & $\mathbf{0 . 0 0 0}$ \\
HDL & $\mathbf{0 . 0 4}$ & $\mathbf{0 . 0 1}$ & 0.9 \\
HbA1c & 0.07 & 0.1 & $\mathbf{0 . 0 0 0}$ \\
Hypertension & 0.06 & 0.34 & 0.001 \\
Waist circumference & 0.27 & 0.11 & 0.69 \\
Metabolic syndrome & 0.04 & 0.35 & 0.02 \\
F change & 27.5 & 19.38 & 36.17 \\
Adjusted R & $27.7 \%$ & $73.2 \%$ & $89 \%$ \\
Significance & $68.7 \%$ & 0.000 & 0.000 \\
\hline
\end{tabular}

Because of collinearity between LDL and TC in all the group, only LDL has been taken. NFS: NAFLD fibrosis score; HOMA-IR: homeostasis model of assessment for insulin resistance; TG: triglyceride; LDL: low-density lipoprotein cholesterol; HDL: high-density lipoprotein cholesterol; HbA1c: hemoglobinA1c. 
significance. As is expected, HOMA IR [OR 1.24 (CI 1.13-1.37)] and HbA1c [OR 5.87 (CI 3.47-12.3)] were positively associated with the diabetic compared to the overall non diabetic group $\left(R^{2} 62.7 \%\right)$.

\section{DISCUSSION}

Thus our study shows that dyslipidemias are strong contributors to the occurrence of NAFLD in non diabetic teetotallers especially those with normal glucose tolerance. $\mathrm{HbAlc}$ in addition is positively associated in the prediabetic stage. However, there is high prevalence of IR also. Previous studies from India has shown the prevalence of IR to be $46 \%-98 \%$, obesity to be $25 \%-87 \%$ (60\%-70\% in most studies) and dyslipidemias to be $44 \%-89 \%$ in the non diabetic NAFLD population with abnormal TC in $22 \%-36 \%$, TG in $23 \%-64 \%$, HDL in $31 \%-66 \%$ and LDL in $25 \%$ cases $^{(2-11)}$. Our study shows similar prevalence of IR, obesity and dyslipidemias with higher TC and LDL levels in such patients. In a previous study ${ }^{(9)}$ dyslipidemia was present in $89 \%$ of lean non diabetics with NAFLD and their lipid levels (TC, HDL, LDL and TG) were similar to overweight and obese NAFLD patients. Also, the prevalence of dyslipidemia was significantly higher in lean NAFLD than the lean healthy controls. In another study high TG was the only factor showing significant association with grade of liver inflammation ${ }^{(5)}$. That such lipid abnormalities are involved in the etiology of NAFLD in non diabetic patients is hinted at in our study by the positive relation of increasing BMI, TG and decreasing HDL with increasing NFS in the NGT subgroup la and that of BMI, LDL, HbAlc, and the presence of the metabolic syndrome (high TG) with increasing NFS in the PD subgroup $1 \mathrm{~b}$ with high $\mathrm{R}^{2}$ value $(73.2 \%$ and $89 \%$ respectively) implying significant contribution. This also indicates that dyslipidemia and obesity have important role to play in the genesis of NAFLD in the non diabetic persons with normal glucose tolerance and IR in addition may come into play during the prediabetic stage. This is further supported by the positive odds of TG, HbAlc and LDL (on binary logistic regression analysis) between the stages of NGT and PD in our study. HOMA IR, though present in the model, just failed to reach significance $(P=0.05)$. One study from China ${ }^{(22)}$ showed that increased serum HbAlc level was significantly associated with risk of NAFLD. The risk was explained by two mechanisms: (a) The level of HbAlc is influenced by life span and "glucose permeability" of erythrocytes. IR in NAFLD leads to increase in hepatic glucose production and export to the peripheral circulation raising the level of serum glucose and hence HbAlc. (b) Oxidative stress in NAFLD which cause erythrocytes to undergo morphology change with decrease membrane fluidity, becoming easy to capture by liver macrophage. This increased erythrocytes destruction increases $\mathrm{HbAlc}$.

Also that our population of non diabetic NAFLD is representative of this group is supported by the positive odds of HOMA IR and $\mathrm{HbAlc}$ in predicting diabetes from non diabetic stage as is normally expected. The interesting finding is that though all the lipid values as well as BMI are higher in diabetic compared to non diabetic NAFLD (as is expected) subjects, they are not significant in the multivariate model implying that lipids may not be involved significantly in its development from non diabetic state.

Thus it appears that in non diabetic persons dyslipidemia, es- pecially high TG and low HDL, either alone or more likely as part of the metabolic syndrome in early stage, influences the development of NAFLD though subclinical IR is also present. Then IR and $\mathrm{HbAlc}$ becomes more important in prediabetic and diabetic state. Thus IR has definite association with NAFLD even in non diabetic people ( $76 \%$ subjects in our study had IR). However, it is important to point out that we estimated IR by HOMA which is an indirect method and has limitations as it reflects hepatic insulin sensitivity (especially in subjects with IFG/IGT). Lean NAFLD patients ( $33.3 \%$ of our cases) have minimal hepatic IR and in them peripheral (adipose tissues and skeletal muscles) IR is more important. Under normal condition, adipose tissues are the primary source $(70 \%)$ of free fatty acids for hepatic TG. Thus, adipose tissue IR may trigger excess release of fatty acids leading to development NAFLD in them ${ }^{(9)}$ again highlighting the importance of dyslipidemia.

Though the age of our cohort was comparable to previous Indian studies but there were more females as opposed to male predominance noted in other studies ${ }^{(2-11)}$. This is possibly due to the exclusion of patients consuming alcohol and all females were teetotallers. This might also have been the cause of male preponderance noted in the above studies which included patients with history of alcohol consumption $(<30 \mathrm{gm} / \mathrm{d}$ in males and $<20 \mathrm{gm} / \mathrm{d}$ in females). The elimination of alcoholics also removed a likely source of bias for high TG levels.

Another interesting finding was the presentation of more than $60 \%$ patients with symptoms of functional bowel disease. Since a common factor to both NAFLD and functional bowel disease is alteration of gut flora, this aspect can also be studied further to decipher its role in the pathogenesis of NAFLD in non diabetic patients.

Our study had certain limitations. We did not study the role of metabolic hormones like serum resistin, adiponectin, leptin and ghrelin in such cases and their roles can be addressed in future studies as also the question whether IR is alone sufficient for development of NAFLD or whether IR and the metabolic syndrome go hand in hand. Secondly there was no follow up data of the patients regarding progress from NGT to PD and from PD to diabetic stage and only predictions from associations could be made. This concept of progress is also not universally accepted and PD may be a different metabolic condition from diabetes. (Only 5\%-10\% PD progress to DM). This is why we included $\mathrm{PD}$ in non diabetic group. Also positive association of IR and $\mathrm{HbAlc}$ may not imply causation. Thirdly due to non availability of fibroscan and consent for liver biopsy, these could not be done though fibroscan has similar limitations as NFS. Nevertheless, significant lipid abnormalities are present in non diabetic teetotaller NAFLD subjects and mandate further study to decipher their precise causative role.

\section{Authors' contribution}

Concept, design, statistical analysis, manuscript editing and critical review was done by Ray G. Literature search, clinical studies, data acquisition and manuscript preparation was done by Agarwala $\mathrm{T}$.

\section{Orcid}

Gautam Ray. Orcid: 0000-0003-4859-8729.

Trilochan Agarwala. Orcid: 0000-0001-6755-4719. 
Ray G, Agarwala T. Estudo de parâmetros metabólicos em pacientes não diabéticos com doença hepática gordurosa não alcoólica - importância da dislipidemia. Arq Gastroenterol. 2019;56(3):270-5.

RESUMO - Contexto - Os fatores de risco metabólicos da doença hepática gordurosa não alcoólica (DHGNA) em abstêmios não diabéticos, que constituem um grupo distinto, não são bem definidos. Objetivo - Identificar os fatores de risco metabólicos da DHGNA em indivíduos não diabéticos e que não consumam álcool. Métodos - Em um estudo transversal, o efeito dos parâmetros metabólicos (IMC, níveis de lipídios individuais, HbA1c, Homa IR e os componentes da síndrome metabólica) de 150 abstêmios não diabéticos consecutivos ( 90 com tolerância à glicose normal e 60 pré-diabéticos) em sua NFS (parâmetro de gravidade quantificável da DHGNA) foram estudados por análise de regressão linear. Um estudo similar em separado foi feito nos grupos normais da tolerância da glicose e do pré-diabetes. Esses parâmetros foram comparados com os de 75 abstêmios diabéticos pareados com DHGNA. Para analisar ainda mais a diferença entre a tolerância à glicose normal foi realizada a regressão logística binária dos fatores tomando pré-diabetes e diabetes como variável de desfecho, nos grupos diabéticos e pré-diabéticos. Resultados - Todos os parâmetros metabólicos foram significativamente maiores nos diabéticos comparados aos não diabéticos e em pré-diabéticos comparados àqueles com tolerância normal à glicose, exceto HDL. Os índices TG, HDL e IMC previram significativamente o NFS no geral nos grupos de tolerância normal $\left(\mathrm{R}^{2}\right.$ ajustado $\left.68,7 \%, P=0,000\right)$ e de glicose normal ( $\mathrm{R}^{2}$ ajustado $\left.73,2 \%, P=0,000\right)$, enquanto o IMC, TG, LDL e HbA1c predisseram em pré-diabéticos ( $\mathrm{R}^{2}$ ajustado $\left.89 \%, P=0,000\right)$. A síndrome metabólica foi associada significativamente com o NFS nos grupos totais e pré-diabéticos. O TG elevado (odds ratio 1,08), o LDL (odds ratio 1,03) e a HbA1c (odds ratio 11,54) foram positivamente associados ao pré-diabetes em comparação com o grupo normal de tolerância à glicose.

Conclusão - Em abstêmios não diabéticos as dislipidemias são os principais contribuintes para o desenvolvimento da DHGNA.

DESCRITORES - Hepatopatia gordurosa não alcoólica. Dislipidemias. Hemoglobina A glicada. Resistência à insulina.

\section{REFERENCES}

1. Amarapurkar DN, Hashimoto E, Lesmana LA, Sollano JD, Chen PJ, Goh KL. Asia-Pacific Working Party on NAFLD. How common is non-alcoholic fatty liver disease in the Asia-Pacific region and are there local differences? J Gastroenterol Hepatol. 2007;22:788-93.

2. Amarapurkar D, Kamani P, Patel N, Gupte P, Kumar P, Agal S, et al. Prevalence of non-alcoholic fatty liver disease: Population based study. Ann Hepatol. 2007;6:161-3.

3. Duseja A, Das A, Das R, Dhiman RK, Chawla A, Bhansali A, et al. The clinicopathological profile of Indian patients with nonalcoholic fatty liver disease (NAFLD) is Different from that in the west. Dig Dis Sci. 2007;52:2368-74.

4. Bajaj S, Nigam P, Luthra A, Pandey RM, Kondal D, Bhatt SP, et al. A case-control study on insulin resistance, metabolic co-variates and prediction score in non-alcoholic fatty liver disease. Indian J Med Res. 2009;129:285-92.

5. Madan K, Batra Y, Gupta SD Chander B, Rajan KD, Tewatia MS. Non-alcoholic fatty liver disease may not be a severe disease at presentation among Asian Indians. World J Gastroenterol. 2006;12:3400-5.

6. Das SK, Balakrishnan V. Role of cytokines in the pathogenesis of non-alcoholic fatty liver disease. Indian J Clin Biochem. 2011;26:202-9.

7. Das K, Das K, Mukherjee PS, Ghosh A, Ghosh S, Mridha AR, et al. Nonobese population in a developing country has a high prevalence of nonalcoholic fatty liver and significant liver disease. Hepatology. 2010; 51:1593-602.

8. Bhat G, Baba CS, Pandey A, Kumari N, Choudhuri G. Insulin resistance and metabolic syndrome in nonobese Indian patients with non-alcoholic fatty liver disease. Trop Gastroenterol. 2013;34:18-24.

9. Kumar R, Rastogi A, Sharma M, Bhatia V, Garg H, Bihari C, et al. Clinicopathological characteristics and metabolic profiles of non-alcoholic fatty liver disease in Indian patients with normal body mass index: Do they differ from obese or overweight non-alcoholic fatty liver disease? Indian J Endocrinol Metab. 2013;17:665-71.

10. Singh SP, Kar SK, Panigrahi MK, Misra B, Pattnaik K, Bhuyan P, et al. Profile of patients with incidentally detected nonalcoholic fatty liver disease (IDNAFLD) in coastal eastern India. Trop Gastroenterol. 2013; 34:144-52.

11. Agrawal R, Mishra S, Dixit VK, Rai S. Association of non-alcoholic fatty liver disorder with obesity. Indian J Prev Soc Med. 2009;40:126-9.
12. European Association for the Study of the Liver (EASL) European Association for the Study of Diabetes (EASD) and European Association for the Study of Obesity (EASO). EASL-EASD-EASO Clinical Practice Guidelines for the management of non-alcoholic fatty liver disease. J Hepatol. 2016;64: 1388-402.

13. Angulo P, Hui JM, Marchesini G, Bugianesi E, George J, Farrell GC, et al. The NAFLD fibrosis score: a noninvasive system that identifies liver fibrosis in patients with NAFLD. Hepatology. 2007;45:846-54.

14. Qureshi K, Clements RH, Abrams GA. The utility of the "FLD fibrosis score" in morbidly obese subjects with NAFLD. Obes Surg 2008;18:264-70.

15. Wong VW, Wong GL, Chim AM, Tse AM, Tsang SW, Hui AY, et al. Validation of the NAFLD fibrosis score in a Chinese population with low prevalence of advanced fibrosis. Am J Gastroenterol. 2008;103:1682-8.

16. Nascimbeni F, Pais R, Bellentani S, Day CP, Ratziu V, Loria P, et al. From NAFLD in clinical practice to answers from guidelines. J Hepatol. 2013;59:859-71.

17. Willet WC, Dietz WH, Colditz GA. Guidelines for healthy weight. N Engl J Med. 1999;341:427-34.

18. Misra A, Chowbey P, Makkar BM, NK Vikram, JS Wasir, D Chadha, et al. Consensus statement for diagnosis of obesity, abdominal obesity and the metabolic syndrome for Asian Indians and recommendations for physical activity, medical and surgical management. J Assoc Physicians India 2009;57:163-70.

19. Waist circumference and waist-Hip ratio: Report of a WHO expert consultation, Geneva. Technical report, World Health Organization. 2008;8-11.

20. Alberti KG, Zimmet P, Shaw J. Metabolic syndrome--a new world-wide definition. A Consensus Statement from the International Diabetes Federation. Diabet Med. 2006;23:469-80.

21. Bonora E, Targher G, Alberiche M, Bonadonna RC, Saggiani F, Zenere MB, et al. Homeostasis model assessment closely mirrors the glucose clamp technique in the assessment of insulin sensitivity: Studies in subjects with various degrees of glucose tolerance and insulin sensitivity. Diabetes Care. 2000;23:57-63.

22. Ma H, Xu C, Xu L, Yu C, Miao M, and Li Y. Independent association of HbAlc and nonalcoholic fatty liver disease in an elderly Chinese population. BMC Gastroenterol. 2013;13:3. 